\title{
The Performance Measures of Primary Health Care Quality: Experiences of Morocco Primary Health Centers during the 'Quality Contest' in 2010-2014 (41 Centers Audited)
}

\author{
Zaadoud B. \\ Biotechnology Laboratory, Environment and Quality, Faculty of Science, \\ University Ibn Tofail, BP 14000, Kenitra, Morocco. \\ Quality Unit, Moulay Yacoub Provincial Delegation, Health Ministry, \\ Morocco
}

Chbab Y.

Biotechnology Laboratory, Environment and Quality, Faculty of Science, University Ibn Tofail, BP 14000, Kenitra, Morocco.

Quality Unit, Directorate Hospitals and Ambulatory Care, Ministry of Health, Morocco

El Ghaza S.

Chaouch A.

Biotechnology Laboratory, Environment and Quality, Faculty of Science, University Ibn Tofail, BP 14000, Kenitra, Morocco

\begin{abstract}
Objectives: The purpose of this article is to discuss the concept of performance measurement in primary health care through a framework called "Quality Contest (QC)." QC is used as a management tool and was implemented from 2007 to improve the quality of the Moroccan health care. The QC encompasses self-assessment, audit, feedback, and the development of improvement plan.

Methodology: The audit peer listed 42 primary health care centers between 2010 and 2014 in four editions. The framework is a self-assessment guide which is made up of 42 items divided into 6 Domains. It was filled by the team of primary health center and a scoring guide for auditors including the expectation horizons.
\end{abstract}

Results: This approach is one recommended in this process (CQ). Performance is evaluated according to the dimensions of the conceptual framework based on the stages of the Deming Cycle (Plan, Do, check, and improve). The overall average performance is $42 \%$ with a minimum score of 
$17 \%$ and a maximum score of $88 \%$. However, the poor performance is noted for the various dimensions: Customer Satisfaction (D1) 39\%, Safety and Responsiveness (D4) 39\%, and Partnership/Community Participation (D6) $39 \%$. The performance according to the steps of the Deming wheel notes a decrease: step plan 61\%, step Do 50\%, step check 34\%, and step improve $14 \%$.

Keywords: Primary health care, quality of care, quality competition, performance measure

\section{Introduction}

Consequently, improving the quality of health care has become a primary goal of all health authorities (Berwick, 2004). Morocco has not lost to this new wave of quality of care that has invaded the world in the eighties of the last century.

After more than ten years in the implementation of health care quality measures, it is time to ask question on the impact of business processes performance qualities in the Moroccan health facilities. The proposed approaches qualities fit into a framework of comprehensive reform of the health system. This reform is defined as a process of fundamental change of policy and institutional arrangements designed by the government to improve the functioning and health sector performance in order to achieve the best results in terms of health status (OMS-AFRO, 1995).

However, the health system is characterized by its complexity: 1) many processes, partly not standard, but are rapidly changing; 2) multiple trades which are constantly evolving; 3) particular sociology, regarding the distribution of the powers of decision; 4) product quality difficult to grasp for professionals and patients; 5) difficulty in identifying and valuing the impact of quality initiatives (ANAES, 2002). 


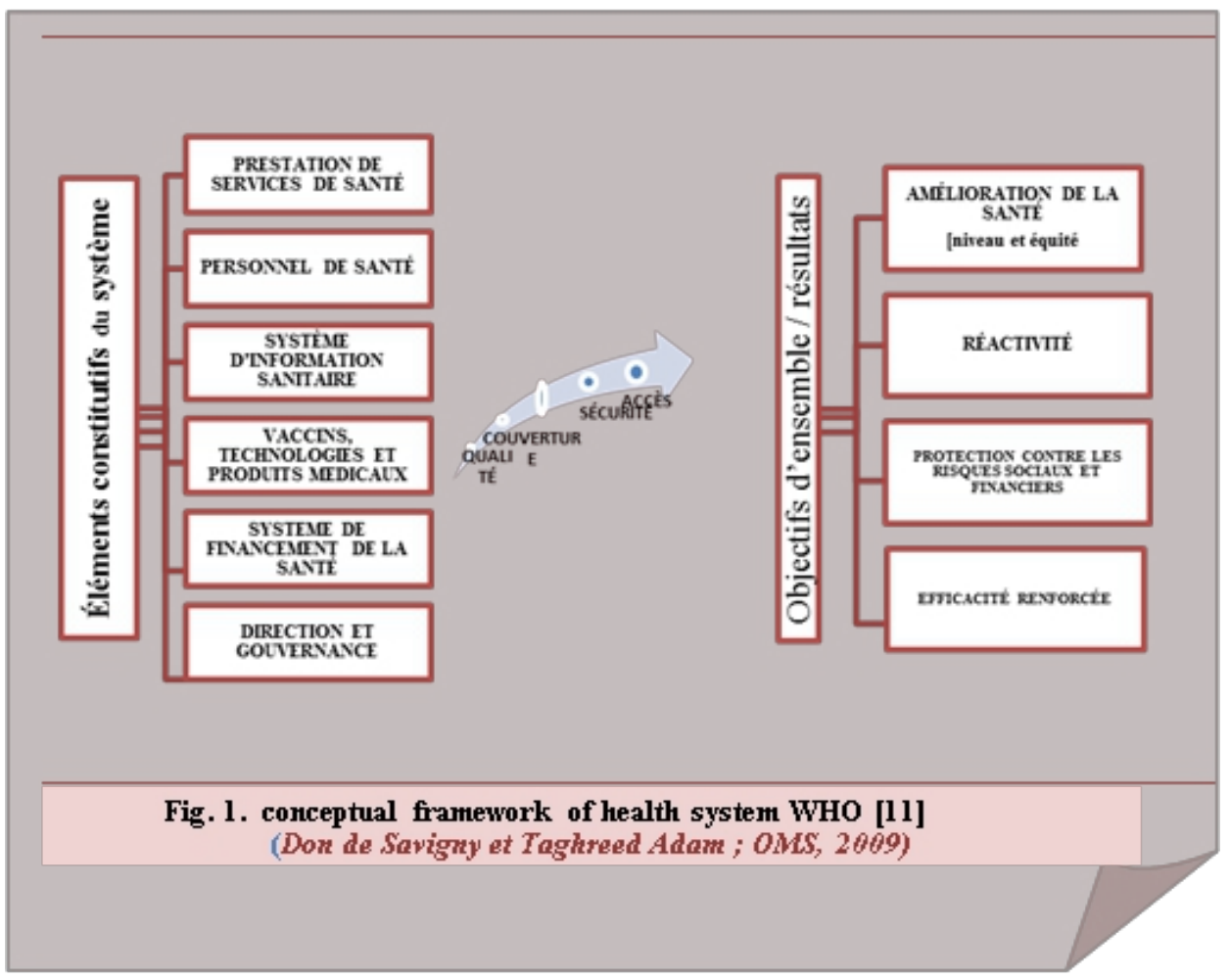

\section{Moroccan Health System}

Several attempts to reform the health care system in Morocco have been initiated since its creation in 1959 at the first conference on health. In order to solve this crisis, the Moroccan health system reforms initiated yards from the 80's (Belghiti, 2008). This is largely related to difficulties encountered based on different types: 1) financial; 2) organizational; 3) acute shortage of human resources and demographic transition; and 4) Epidemiological (Belghiti, 2008). A recent analysis of the Moroccan health system has identified five dysfunctions (Moroccan Strategy, 2012). These dysfunctions include: 1) Lack of access to health care for the population, especially those in remote rural areas; 2) The very large deficit in human resources; 3) Lack of funding; 4) A crisis of confidence of the population towards their health systems; 5) Deficit in governance. Thus, the aim of the reforms is to prepare it to better meet the increased demand for care (Belghiti, 2008).

This is carried out so as to support the efficiency of services and the balance between resources and results. The health system is defined by WHO as "All activities whose primary purpose is to promote, restore, or maintain health" (OMS, 2000) (WHO, 2000). In Morocco, "The provision of care is composed of the infrastructure and fixed or mobile health facilities in 
the public sector and the private sector, human resources allocated to them, as well as resources used to produce response and care services benefits to individuals' health needs, families and communities" (Law 34-09). Art 9 Healthcare provision is governed by principles which are eight in number. They are: 1) Solidarity and empowerment of the population; 2) Equal access to health care and services; 3) Equity in the spatial distribution of health resources ; 4) Inter sectoral complementarities; 5 ) Adoption of the gender approach of health services; 6) Integration and coordination; 7) overall; and 8) Gradation of care. Consequently, the health system is based on the function approach (Law 34-09): 1) Provision of health services; 2) Personal services; 3) Health information system; 4) Vaccines, Technology and Medical Products; 5) Health financing system; 6) Management and governance (Don de Savigny, 2009) (Figure 1).

Furthermore, the organization of health care in Morocco offers many forms: By sector: public, private; By networks of health facilities: RESSP (Networks of the primary health care), HR (Hospital networks), RISUM (Network integrated of the emergency care), and REMS (Medical and social network of establishments); For health programs; By health territories; For health coverage modes: fixed, mobile; By care pathways; and By coordinated care networks. The health care system in Morocco is Pyramid, Integrated, Tiered, and is based on Primary Health Care (Law 3409).

\section{The Goal of the Study}

The objective assigned to CQ was double. They are: a) improve the service provided to the beneficiaries, and b) set up a dynamics of institutional change based on the reinjection of the results of the field work to the teams, the in-service training of the volunteers, and what should in return improve the quality of the service provided and also the bonus of the volunteers (Kelley, 2001). However, one of the advantages of the process approach is the control perm that she allows based on the relations between the individual processes within the system, as well as on their combinations and interactions.

When it is used in a management system based on quality, this approach underlines the importance a) to understand and to fill the requirements; b) to consider the processes in terms of added value; c) to measure the performance and the efficiency of the processes; and d) to improve permanently the processes on the basis of objective measures. It targets the process and not the product (ISO-9001, 2008). The purpose of this article is to analyze the performance in primary health care through a framework called competition quality which is used as a quality management tool in Morocco. From 2007, it was implemented so as to improve the quality of 
health care in Morocco. However, one of the questions to be answered is what is the best way to measure performance in the field of the quality of care? Also, the results were compared with the experiences of previous evaluations Project of Quality assurance (QA) in Morocco.

\section{Definitions and Concepts}

\subsection{Quality of Care:}

Berwick translated the objectives of "Quality Chasm" according to the perspectives of the patient: "Credit note of health care, without useless deaths, without useless sufferings, without pain, no unwanted wait, no powerlessness, and no waste" (Berwick, 2004). "Make the good thing, at the right time, in the right direction, for the good person to obtain the possible better results" (Agency for Healthcare Research and Quality). The WHO stated: "The quality is an approach which has to allow or guarantee every patient the assortment of diagnostic and therapeutic acts which will insure a better result in term of health, according to the current state of the medical science, to the best cost for the same result, to the slightest iatrogénique risk, and for its biggest satisfaction in term of procedures, results (profits), and of human contacts inside the system of care" (Virginie, 2010). The Institute of Medicine (IOM) defines quality as being «the capacity of health services intended for the individuals and for the populations to increase the probability to reach the desired results of health, in accordance with the professional knowledge of moment" (IOM, 2001). Therefore, it recovers five components: the medical efficiency, the efficiency to make good things, and to reach the goals; the conformity with the scientific standards admitted by the highest authorities on the subject; the adequacy between the offer of service (performance) and the needs for the sick; the surety (minimum of risks for the sick person); the economic efficiency allows equal quality and an optimal use of the available resources (HAS, 2012).

\subsection{Primary Health Care Sectors (SSP):}

The systems of primary care are the kingpin of health systems is allying effectiveness and efficiency (Starfield, 2005). It was demonstrated that primary care play a very important role in the health system. It performs a role of preventing diseases and reducing complications and deaths. They are associated to a fairer distribution of the health within the populations. The goals for interdisciplinary collaboration in PHC are: 1) A client-care focus that encourages patients/clients and communities to assume more responsibility for health; 2) A multi-faceted approach that ensures quality of care and builds on existing strengths and evidence; 3) Structures which facilitate 
teams learning of new ways of working together in a trusted environment; 4) A clear flexible structure that promotes enhanced communication and respect for the role of personal judgment, and that encourages each team member to make use of his/her skill (Karen, 2012). When we measure the yield (efficiency) on the services of primary care in a similar way, it is possible to determine what factors are associated to better results (William, 2011). The strategy of the primary health care was introduced by the conference of Alma-Ata in 1978. Thus, this was traced as the first objective; "Health for all before the year 2000". Furthermore, it was defined by the World Health Organization (WHO) in 1978 as: "essential health care based on the practical method, scientifically valid and socially acceptable and of the technology: universally accessible to all in the community with their full participation; in an affordable cost; and directed to the autonomy and the self-determination" (Lisa, 2012). The objective of the primary health care is to: "Insure the access at the appropriate time to healthcare and to the quality of health services according to the methods based on scientific obvious facts (Lisa, 2012).

\subsection{Quality Approaches:}

An increasing number of quality models and approaches were developed during the last few decades. (Lanier, 2003). Although having the same objective, the interventions and the principles which underlie these surrounding areas of quality were rather varied (Ovretveit, 2003). However, the quality systems can target the performance of the person receiving benefits only, or might target the performance of the whole organization. They can concentrate on the procedure or on the results of the care, use the self-assessment or the external audit, and supply a feedback in private or publish results. The evaluation of the quality of an action concerns three elements: the structures (average human beings, material, financial), the procedures (manners to make), and the results (realizations, impacts, side effects) (Virginie, 2010). In the medical domain, it can be translated by: 1) estimating the satisfaction of needs and the protection of the beneficiaries; 2) estimating the expertise and the organization of the technical actions of the assistance, in particular the good use of the resources; 3) analyzing the impact of the action on the situation and the safety (security) of the actors. This, however, can be the evaluation of the best balance between the satisfaction of needs and the available expertise; 4) encouraging the comparisons to benefit from the experiences (experiments) of others; 5) learning according to the cycle of Plan-Do-Check-Act proposed by Deming; and 6) improving as a result of creativity (Virginie, 2010). 


\subsection{The Performance:}

The performance is a multidimensional concept (Sicotte, 1998) which is complex (Julien, 2007) and difficult (dreaded). Therefore, there are numerous definitions of the performance (Villarmois, 2001). Sicotte (1999) defined it as "Incomplete and split up by the organizational performance" (Sicotte, 1999). Indeed, the study of the organizational performance is a concept historically difficult to define because of its complex, multidimensional, and paradoxical nature (Fernando, 2011). Seven themes were identified by Campbell as the key domains for the development of performance indicators: the experience of the patient, the clinical activity, the development of the services and the innovation, the access, the promotion (class) of the health, the efficiency of the costs, and the quality of the results of the life (Campbell, 1999). The WHO identified six criteria with which a health system has to answer before being considered as an establishment that is providing medical health care of very high quality (WHO, 2006). Furthermore, a health system tries to drive improvements in six domains or dimensions of quality: 1) The service (performance); 2) Effective; 3) Accessible (Approachable); 4) Acceptable/centered on the patient; 5) Fair; and 6) Sure and Safety (Security) (IOM, 2001; WHO, 2006). Subsequently, Morocco took the same elements of the definition of the bodies: Effective: provide medical health care resting on scientific knowledge updated and which is recognized to contribute to the improvement of health conditions (GTZ, 2011). Efficient: optimize the use of the available resources and avoid wasting; Accessible (approachable): provide medical care which are convenient and suited to patients in contexts where the skills and the necessary resources are available; Acceptable/ centered on the patient: meet the needs of patients and those of their families based on their preferences and social and cultural sensibilities; Fair: Supply medical care in a way to minimize the risks and the damage. Therefore, most of the definitions of quality are similar, except that sometimes, the safety (security) and the experience of the patients are added (BORGËS, 2011).

\section{The Moroccan Experiences in the Field of the Quality of the Care}

\subsection{Demography of Morocco:}

The total population of Morocco is about 33.8 million inhabitants. The annual demographic growth rate is estimated (esteemed) at 1, 0\% (2001-2012) and the median age is 27 years. About $30 \%$ of the population is less than 15 years old. The life expectancy in the birth was of 74.8 years in 2012 (74.3 years for the men (people) and 76.2 years for the women). The distribution of the population by sex is balanced, and 
the women represents more or less 50,5\% of the population (Morocco, 2016).

5.2. In Morocco, pilot experiments for the improvement of quality were implemented (operated) at first in health services in the 1990s. Thus, this was with several tested approaches (quality circles, Problems Resolution Team Approaches, clinical audits) (Blaise, 2005).

5.3. In 2005, Morocco opted for a quality approach called "Competition Quality" (QC) targeting health centers, hospitals, and delegations of health. This approach combines (organizes) between the measure of the quality of the structures; their classification, the disclosure of the performance, and a system of reward. Morocco, however, made a commitment very early in the search (research) to solve the problems of the quality of health care (Siddiqi, 2012). QC which was inspired by the approach of the improvement of the systematic quality, developed by the German Agency of technical cooperation (Schneider, 2007), knew the starting up of the first publishing in 2007.

\subsection{The Contest Quality $(Q C)$ :}

At the end of the $90 \mathrm{~s}$, the Ministry of Health registered the component "Improvement of the quality of the care and the services (departments)" as strategic actions. This action is centered on politics aiming at strengthening the quality and the efficiency of the care and the services (departments). Consequently, a National Program of Quality assurance (PNAQ) was born (PNAQ, 2000). The PNAQ is based on a functional approach and it divides the functions of the health system into two groups. The first group is the technical functions which are among three; define, Measure and Estimate. On the other hand, the second group refers to the functions of support which are in number of six; the documentation, the training, the facilitation, the incentive, the motivation, and the communication (GTZ, 2012). System Quality Improvement (SQI) is an instrument developed by GTZ, and is conceived (designed) to improve the quality of a whole system ceaselessly. In 2004, the GTZ worked with the Ministry of Health in Morocco to conceive and set up a quality approach inspired by System quality improvement (SQI). The SQI is called Competition Quality (QC) which is intended to support the efforts of the country in the decentralization and the reform of health services. Subsequently, the accent put itself on the improvement of the maternal health and the fight against the infant mortality (GTZ, 2012). The QC is an approach that is based on the systematic approach of improvement of the quality of the care. It focuses on the quality of the process which helps to facilitate organizational development and at a better functioning of the system. It addresses the public structures of care 
(hospitals and health centers) and the sanitary administration (the provincial and prefectural delegations). Therefore, the competition bases itself on the evaluation of performance by the dimensions of the definition which was inspired by the national politics. In addition, various aspects follow the cycle of the wheel of Deming: plan, Do, check, and Act. Five dimensions are common for 3 types of participating structures. These dimensions include: satisfaction of the users; accessibility, availability, and continuity; rationalization of the resources; safety (security)/reactivity; and continuous improvement. The guiding principles of Competition Quality were developed (GTZ, 2011). 1) The process approach; processes of better quality leads to better results. The term "process" is defined as "A set of activities which take place inside and between the practitioners and the patients" (Donabedian, 1980). 2) To commit the whole system, the lowest (weakest) units of a system weaken its strongest units. The units reach a better result when they are a member of one that is integrated quite well. 3) To Maintain Voluntary participation. 4) To improve the system of rewards; congratulate on the participation and reward to improve the performances (Véronique, 2003). Furthermore, it comes in three phases: 1) the Constitution of the reference table of the practices (guide of self-assessment) developed from standards and from criteria; 2) Elaboration of measurement tool from determined criteria (guide of scores); and 3) Analysis of the results to assess the differences between the practices observed and the defined practice (measuring performance) (GTZ, 2011).

\section{Methodology}

\subsection{Measure of the Performances:}

The measurement of performance is a complex and multidimensional operation (Campbell, 2000). In the field of the care, the measurement of performance is sometimes very controversial. Although health services are considered as one of the leaders regarding the measure and surveillance of the bound problems, there is no real national frame of the evaluation of the performance. In fact, it has to do with a multitude of initiatives which were thrown (launched) publicly or were deprived. The domain of the management will have to evolve as a Lose sight. This shows the quality of the services (departments) and the satisfaction of the users. Also, they will be left by fundamental dimensions based on the evaluation of the performance of health and social services (Danielle, 2008). The conceptualization of the performance directed on the processes shows the values of the patients or the professionals with the quality, the purposes to be reached, and the adaptation to the environment (Smits, 2008). Several models of the measurement of 
performance which are based on the integration of Seven key themes for the development of performance indicators were developed. These entails the experience of the patient, the clinical activity, the development of the services and the innovation, the access, the promotion of the health, the efficiency of the costs, and the quality of the results of life (Fernando, 2011). 1) A Margaret E.K et al. model (2008) was based on the evaluation of the performance of the structures of primary health care. The evaluation of the performance of the structures of care will be made by the analysis of four dimensions: the effectiveness, the efficiency, the equity, and the satisfaction by taking into account the environment of the organization (Margaret, 2008). 2) A WHO model, based on the efficiency and "the results obtained according to the resources established the real measurement of performance of a health system" (WHO 2006). This approach was used more and more in the field of health when the safety became a concern in the discussions about the reforms of the health system (IOM, 2001). 3) A Donabedian model (1988), proposes four levels of evaluation: a) the quality of the care realized by the nursing staffs, b) the quality of the infrastructure of the sick person reception, c) the profit brought to the patients and to their families, and d) the quality of the service care at the level of a territory (accessibility, continuity, coordination) (Donabedian, 1988). 4) A multidimensional model of the performance is affected by the efficiency and the effectiveness of their activities (Contandriopoulos, 2008). The performance is often understood as a concept which includes all the following notions: efficiency, effectiveness, yield, productivity, quality, access, and equity. Thus, it is based on the organizational performance (Champagne, 2005). 5) The EGIPSS model rests on the use of best quality indicators to improve the performances of the system. These indicators have to do with the accessibility, the continuity, the global nature, and the productivity of the care. Every indicator is a reflection of the clinical and organizational practices, and also the availability of the resources and the particular environment. Hence, it must be analyzed in this context. 6) A Kaplan and Norton model (1998) developed a model of balanced scorecard which takes into account several dimensions of the performance. Therefore, it proposes four axes which allow the establishment of a balance between the long-term objectives, the desired results, and the determiners of these results between objective measures and subjective measures. These axes include: the financial axis, the customer axis, the internal processes axis, and the organizational learning (apprenticeship) axis. A measure of performance is an indicator in connection with the factors of success and the strategic objective. Thus, it is used to judge the functioning of a precise process. These indicators 
supply the references used for measuring the progress of a strategic objective. They are essential in the transformation (processing) of the strategic plans in actions. To deduct the actions from it to be led, they supply to the persons in charge of the wanted signals. This was performed based on the measure of the progress of the processes and on the comparison of the results of the standards. That is why performance indicators make measurable the vision and the objectives. Total Performance Scorecard (TPS) is a continuous, gradual, and a systematic process of improvement which involves development and learning. To improve, to develop, and to learn are three foundations of a global management established according to the principle TPS. Thus, they are closely mixed. Also, the balance between them must be maintained. THE OBSC integrates the continuous improvement, the control of the processes, as well as the elaboration of the strategy directed on the acquisition of competitive advantages for the company. The cyclic process of continuous improvement in TPS focuses on the gradual improvement of the methods of work, the skills, and the behavior of the employees by basing itself on the learning PDCA (Hubert, 2005). 7) A Performance Assessment Tool for quality improvement in Hospitals model (PATH) is a model that has six dimensions which were identified for assessing hospital performance: clinical effectiveness, safety, patient centeredness, production efficiency, staff orientation, and responsive governance. The following outcomes were achieved: a) definition of the concepts and identification of key dimensions of hospital performance; b) design of the architecture of PATH to enhance evidence-based management and quality improvement through performance assessment; c) selection of a core and a tailored set of performance indicators with detailed operational definitions; d) identification of trade-offs between indicators; e) elaboration of descriptive sheets for each indicator to support hospitals in interpreting their results; f) design of a balanced dashboard; and e) strategies for the implementation of the PATH framework (Veillard, 2005). 8) The OECD model performance of the primary care is divided into two main components: 1) the service delivery of health care which is defined as the way the services of health care are distributed and 2) the technical quality of the clinical care which is defined as the measure in which the clinical procedures reflect the data of current search and/or they usually meet the standards accepted for the technical contents or of skills (OCDE, 2011). 
BoX 1. Quality Competition Stages.

Stage 1. Recruitment and preparation of the porticipoting structures of heolth.

Stage 2. Self-assessment by means of questionnoires.

Stage 3. Quality onalyzes questionnoires of self-assessment by the team of evaluation of the Competition.

Stage 4. Evaluations by troined peers of heolth

Stage 5 . At the end of the visit of the evaluation of the peer, a plon of improvement was prepared by the stoff of the structure.

Stage 6. Meto anolysis and allocation of the prices.

Stage 7. Improvement Plons implementotion by porticipoting

The measure of the yield (efficiency) in the primary care can serve two main objectives: improve the quality and the promotion of the responsibility (OCDE, 2011). Various objectives for the measure of the yield (efficiency) in the primary care were harmed (served) by various tools and approach. 9) The IOM model is a conceptualized quality as six dimensions: safety, timeliness, effectiveness, efficiency, equity, and patient centeredness (IOM, 2001). It leans strongly on the prospect of the comparison for the measurement of performance. Also, the improvement of the performance passes the possibility of revaluing and adjusting the strategies, the programs, the politics, and the associated objectives (Vieillard, 2010).

\subsection{Methods.}

Our introductory question of the subject of search (research) is: Does the implementation of a quality approach (CQ) have an influence on performances of health centers? To answer this question, we opted for an abstract frame that is based on the systematic approach, which has double objective: 1) Dispense to the sick of the quality care and 2) Contribute to the control (master's degree) of the costs and the planning of health care. The abstract frame (executive) was subdivided into dimension based on a system 
of measure and credible, relevant, objective, and transparent report (relationship) (McGlynn, 2002).

\begin{tabular}{|c|c|c|c|}
\hline Score & Min & Moy & $\operatorname{Max}$ \\
\hline $\begin{array}{l}\text { General } \\
\text { Performan }\end{array}$ & $17 \%$ & $42 \%$ & $88 \%$ \\
\hline
\end{tabular}

The High Authority of Health opted for a structuring of its criteria according to the wheel of Deming (Plan - Do - Check-Act); however, this process favors the continuous improvement (Bruxelles, 2013). The choice of the model of the improvement of the quality by an institution has to take into account, at the same time, its expected efficiency and acceptance by the healthcare professionals. These include: the audit of the professional practices, the cards of control, and the quality circles which are the tools to answer best this double requirement (Guy Haller, 2014). The CQ opted for the process approach according to the wheel of Deming, which understands seven stages (Box 1). Subsequently, the dimensions identified: the Customer satisfaction (D1); the Accessibility/Availability/Continuity (D2); the Rationalization of the resources (D3); the Safety (Security) and Reactivity (D4); the Leadership and Continuous improvement (D5); and the Community Partnership/participation (D6). Every dimension was subdivided into various aspects, describing the quality level to be reached. Every aspect was divided then into several questions which were formulated according to the stages of management of the wheel of Deming: plan, execute, estimate, and adapt (Deming, 1986) (Figure 2). The structural domain describes the system of health care, the context, and the organization of the practice in which an organization of primary care operates based on the practice. The domain of the performance includes features of service offer of health care and the technical quality of the clinical care. The Audit was done in 41 health centers in 19 urban areas and 22 rural areas in the country. Also, a center refused to welcome the listeners for administrative reasons. The Audit is made by binomial and it lasted for one day with a pre-established program (Box 2). 


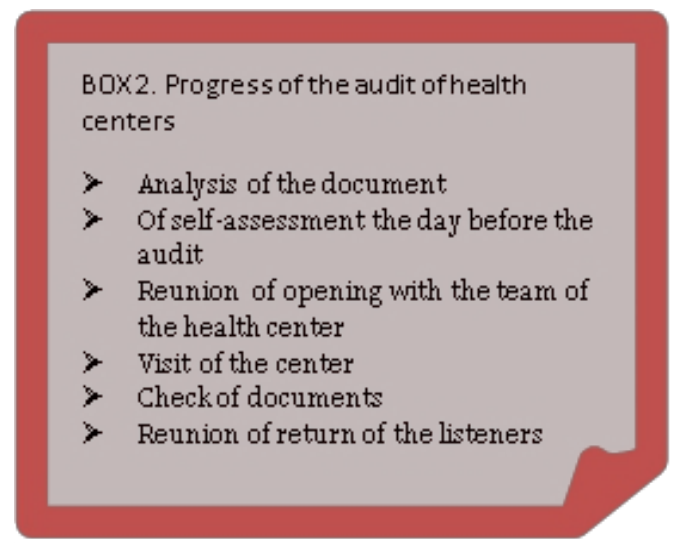

\section{Result}

The results of the audit of 41 health centers among 42 (a center refused the audit for administrative reasons) will be presented according to the performances global. These performances are according to the dimensions and the stages of the wheel of Deming. The centers which participated left (restarted) between the urban areas (19) and the rural area (22). The average number of the staff who was working was 5 people with a maximum of 13 people and a minimum of 3 people.

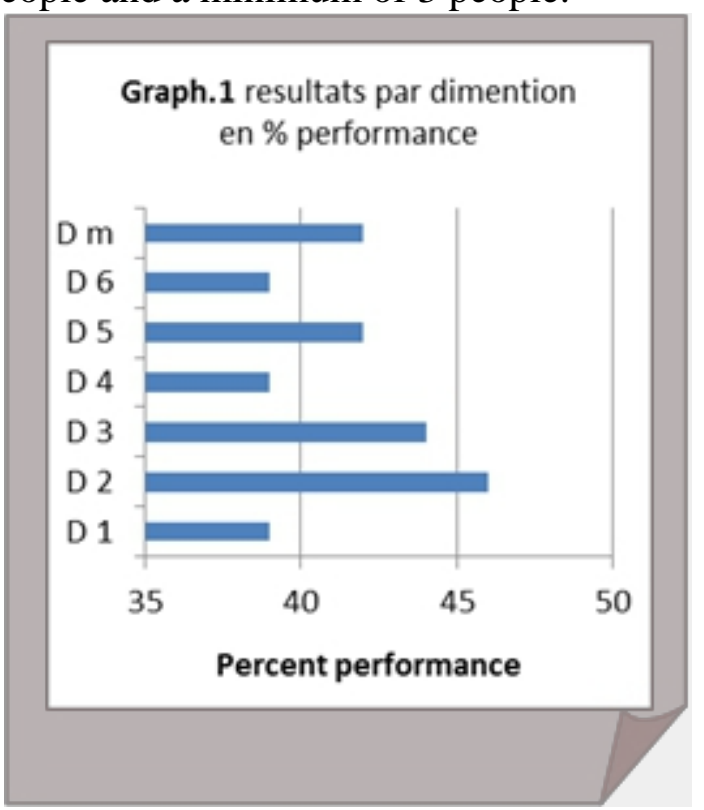

7.1. The global performance (Table.1) varies between $17 \%$ for the minimal and $88 \%$ for the maximal with an average of $42 \%$.

7.2. The performance according to the dimensions (Graph 1). The evaluation of the performance of the structures of primary health care passes by the appreciation of elements and technical services of 
the structure. Thus, this is achieved by taking into account dimensions of the CQ. The result by dimension shows that $50 \%$ of the dimensions have a lower score with an average of $42 \%$ : customer satisfaction (D1) $39 \%$, Safety and Reactivity (D4) 39\%, and Community Partnership/participation (D6) $39 \%$. On the other hand, $50 \%$ have a score which is more than the averages: accessibility/Availability/Continuity (D2) $46 \%$, rationalization of the resources (D3) $44 \%$, and Leadership and Continuous improvement (D5) $42 \%$.

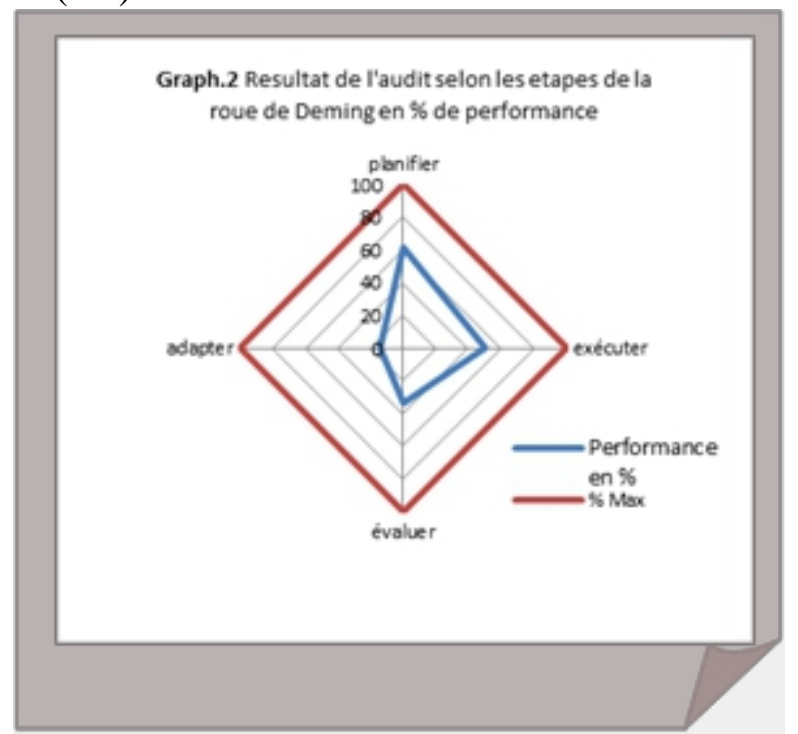

7.3. The performance according to the stages of the wheel of Deming (Plan - Do - Check-Act) (Graph 2). The result of the audit according to the stages of the wheel of Deming was $61 \%$ for the stage to plan; $14 \%$ for the stage to adapt; $50 \%$ for the stage to execute; and $34 \%$ for the stage to estimate. The stages of evaluation and improvement require more experiences and the control of the complex tools which are lacking at the majority of the staff who practices in health centers.

7.4. The graphic representation by Box plot (Graph 3) shows the minimal alignment of the performance for all the dimensions. However, we note a significant variation for the maximal performances. This includes the median which is near $48 \%$, whereas the average does not exceed (overtake) the $42 \%$ this owed due to the bad dispersal of the scores of the CS. 


\section{Discussion}

In the first place, the effect to launch a process of quality improvement can be only beneficial for the system of care. Thus, a well led evaluation was recognized as a fundamental element for the improvement of the practices (Bradley, 2004). The importance to measure and to estimate the quality of the strategies of prevention helps: 1) for better encircling of their operating mechanisms as well as their advantages and potential risks; 2) to measure their impact and their degree of adequacy; and 3) to estimate their utility with regard to the reduction of the disparities of health (Starfield, 2009). If certain countries failed to reach their goals, others were successful (succeeded) (Bradley, 2012). Our studies showed the same noticed of the other initiatives of the evaluation of quality approaches implanted in Morocco. Thus, we speak about "results of process" and not the results of evaluations of impacts on the health systems of countries (GTZ, 2012). The accreditation hospitable (hospital) has a supplementary approach (initiative) introduced in the breasts of the hospitals of Morocco. This has certainly brought about many positive changes. Also, the constraints remain almost the same such that those met based on other experiences on an international scale were concluded upon (Mohssine, 2012). Thus, the approach qualities became the main mechanism of the country for a follow-up, an evaluation, and the improvement of permanent employees of the systems and structures of health (GTZ, 2012). International studies showed the same conclusions of Macinko and Starfield (Macinko, 2003; Starfield, 2002). The teams were very satisfied with their work on the improvement of the quality (Starfield, 2013). Also, other study showed that the health systems of the countries of the African region show weaknesses in the service (performance).

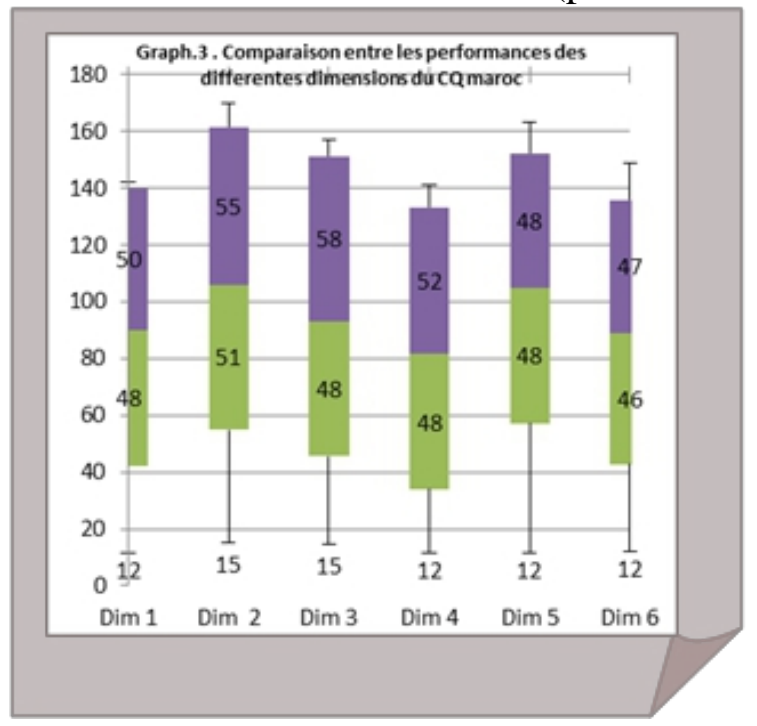


This, however, lift multiple challenges which can be included under five major themes: leadership and governance, organization, sanitary information, financing, and human and material resources (Amidou BabaMoussa et al.). Therefore, two main reasons were called to explain this relative failure: 1 )

The description of the processes was perceived as very complex, and 2) The complexity of the establishments of health which is characterized by: a) numerous processes, partially not standard but with a fast evolution; b) multiple jobs and in permanent evolution; c) a particular sociology, in particular, as regards the distribution of decision-making powers; D) a quality of products of the freed (delivered) care is difficult to arrest (dread) for the professionals and the patients (ANAES, 2002). Consequently, Bradley identified certain conditions necessary for the feedback to promote the change: 1) the perception (collection) by the professionals of the validity of the communicated information, 2) the credibility of these identified problems and the way of giving the feedback and presenting the evaluations (Bradley, 2004). Furthermore, the recognition of the efforts were indicated as factors (mailmen) of valuation and motivation affecting (allocating) the durability of the performance at the healthcare professionals (Dieleman, 2006). The comparison of the performances between hospitals seems to be associated to an improvement of the procedures of care (Merle, 2009).

However, the participation in competitions with the aim of winning a prize can represent an incentive for the professionals to improve their procedures and services (departments) (Milakovich, 2004). The accreditation is an ambiguous process. On one side, the actor is subjected (submitted) in a set of references of bureaucratic type (chap) (Crozier-Friedberg). On the other side, the actor is in the center of the process of participative management established by the accreditation. Various approach qualities including the "CQ" offers to the professionals the opportunity to rethink the modes of treatment (processing) and the operational modes in a collective way rather than hierarchical (Husser, 2002). The healthcare professionals are beginning to become acquainted with the notion of self-assessment, and to introduce a program of continuous improvement of the quality (Pomey et al., 2004). Consequently, many nursing staff has a negative image of the accreditation (HAS, 2010). Also, a well led evaluation was recognized as a fundamental element for the improvement of the practices and the effects of the check and the feedback are generally considered as being lowly moderated (Bradley, 2004; Jencks et al., 2003). In our series, the evaluation stays low at $32 \%$ with a percentage of improvement which does not exceed $14 \%$. Finally, in order to use a health system framework for performance assessment, there must be a clear way to determine how 'good' a health system is as regards to its performance. 


\section{Conclusion}

In conclusion, the performance measure in health care remains very difficult and the lack of valid framework complicates this action. The staffs, who work in the primary health care center, suffer from an important lack for the tools to improve the health care quality. The quality contest is a process approach that does not give importance to the results and the effects. The improvement of the primary health care is necessary to pass by the performance measure and search for appropriate evaluation tools.

\section{Limits}

The limits of this study can be represented by the following elements: 1) lack of exhaustiveness with regard to the current evaluation tools. 2) the evaluation of reliability and validity of the qualitative studies remains difficult has to appreciate. 3) most of the evaluation tools of the primary health care are not validated yet. 4) The search for primary health care remains limited with regard to hospital care. 5) The difference in performance levels between Morocco and the other countries, especially for the developed countries and the multitude of the frames of measure of performance, limits the comparability of the results.

\section{References:}

1. Amadou Baba-Moussa et al. «Renforcement des systèmes de santé dans les pays de la région africaine de l'OMS : Répondre au défi ». Bureau regional de l'OMS pour l'Afrique, Brazzaville. Health Systems and Reproductive Health. Special Issue 14.

2. ANAES (2002). «Principes de mise en œuvre d'une démarche qualité en établissement de santé ». ANAES/Avril.

3. André-Pierre Contandriopoulos et al. (2008). «L'amélioration de la performance : un enjeu central pour les CSSS ». Par Infolettre Volume 5, Numéro 2, Mai.

4. Agency for Healthcare Research and Quality.

5. Berwick (2004). "Lessons from developing nations on improving health care". BMJ 2004;328:1124

6. Belghiti Alaoui A. (2008). "La réforme hospitalière au Maroc "; Revue Gestions hospitalières, $N^{\circ}$ 472, pp.52-55 Paris (France).

7. Blaise, P. (2005). "Culture qualité et organisation bureaucratique, le défi du changement dans les systèmes publics de santé, Une évaluation réaliste de projets qualité en Afrique", $\mathrm{PhD}$ Thesis, Université Libre de Bruxelles, Brussel.

8. BORGÈS DA SILVA R ET AL (2011). «Pour une approche globale de l'évaluation de l'utilisation des services de santé : concepts et 
mesures $»$. PRATIQUES ET ORGANISATION DES SOINS VOLUME $42 \mathrm{~N}^{\circ} 1$ / JANVIER-MARS.

9. Bradley et al. (2004). "Data feedback efforts in quality improvement: lessons learned from US hospitals". E H Bradley, E S Holmboe, J A Mattera, S A Roumanis, M J Radford, H M Krumholz. Qual Safe Health Care.

10. Bradley, E.H. \& Yuan, C.T. (2012). "Quality of care in low- and middle-income settings: what next?" International Journal of Quality and Health Care, Vol. 24 No. 6, pp. 547-549.

11. Bruxelles (2013). «L'accréditation des hôpitaux. L'indispensable phase d'éveil ». 31 octobre.

12. Campbell S.M., M.O. Roland, \& S.A. Buetow; (2000). "Defining quality of care" Social Science \& Medicine 51.

13. Champagne F et al. (2005). «Un cadre d'évaluation de la performance des systèmes de service de santé : Le modèle EGIPSS » N05-02 Avril. Université de Montrial. Canada.

14. Danielle McCann (2008). « La gestion de la performance, un outil de changement organisationnel ou le changement organisationnel un outil pour la gestion de la performance ». Volume 5, Numéro 2, Mai; infolettre.

15. Dieleman, M., Toonen, J., Toure, H. \& Martineau, T. (2006). "The match between motivation and performance management of health sector workers in Mali”, Human Resource for Health, Vol. 4, No. 2, pp. 23-27.

16. Donabedian A. (1988). "The Quality of Care. How Can It Be Assessed?" Journal Of American Medical Association, n²60, Vol. 12 , p. $1743-1748$.

17. Don de Savigny \& Taghreed Adam (2009). «Pour une approche systémique du renforcement des systèmes de santé ». Alliance pour la recherche sur les politiques et les systèmes de santé, OMS.

18. Donabedian. A. (1980). "Explorations in Quality Assessment and Monitoring: The Definition of Quality and Approaches to Its Assessment”. Health Administration Press, Ann Arbor, Michigan, $\mathrm{n}^{\circ}$ 1.

19. Évaluation des fonctions essentielles de santé publique (2016). Rapport technique réalisé par le ministère de la santé et l'Organisation Mondiale de la Santé Au Maroc. Janvie.

20. Fernando Miguel Rivas Olivares (2011). «Un modèle global et intégré de la performance: application à l'urgence d'un hôpital au Mexique $\gg$.

21. GTZ (2011). «Améliorer la qualité des soins ». 
22. GTZ (2012). «Améliorer le système de santé. Approches au Maroc et au Yémen ». One publication de la German Health Practice Collection.

23. Guy Haller, Jean-Luc Quenon (2014). Démarches qualité à l'hôpital : laquelle choisir ? Revu Med Suisse 2014;10:1143-1147.

24. HAS (2010). «Analyse de la littérature sur l'impact des démarches de certification des établissements de santé ».

25. HAS (2012). Guide méthodologique de diffusion publique des indicateurs de qualité des soins.

26. Hubert K. Rampersad (2005). « Total Performance Scorecard, réconcilier 1'homme et 1'entreprise ». Springer-Verlag France, Paris.

27. Institute of Medicine (2001). "Crossing the Quality Chasm: A New Health System for the 21st Century". The National Academies Press.

28. ISO (9001). «Systèmes de management de la qualité, Exigences ». Quatrième édition Numéro de référence ISO 9001:2008(F).

29. J. Husser (2002). «Le pilotage du changement par l'encadrement intermédiaire : le cas de l'accréditation à l'hôpital ». Thèse de sciences de gestion, université Montesquieu-Bordeaux IV, 12 décembre.

30. Jencks et al. (2003). "Change in the Quality of Care Delivered to Medicare Beneficiaries, 1998-1999 to 2000-2001." Stephen F. Jencks, MD, MPH; Edwin D. Huff, PhD; Timothy Cuerdon, PhD.

31. Julien CAMBON (2007). «vers une nouvelle méthodologie de mesure de la performance des systèmes de management de la santesécurité au travail » thèse de doctorat de l'École des Mines de Paris le 9 novembre.

32. Karen Eider (2012). "Primary Health Care is a Collective Responsibility”. SRNA News Bulletin winter.

33. Kelley, E., H. Abdullah, A. El Karimi, \& E. Knebel (2001). Quality improvement teams in Morocco: An evaluation of functionality and success. Operations Research Results 2(1). Bethesda, MD: Published for the U.S. Agency for International Development by the Quality Assurance Project.

34. Lanier, D.C., Roland, M., Burstin, H. \& Knottnerus, J.A. (2003). "Doctor Performance and public accountability", Lancet, Vol. 362 No. 9393, pp. 1404-1408.

35. Lisa Dustyhorn SIHL (2012). "A PRIMARY HEALTH CARE SETTING PROJECT”. APRIL 1.

36. Loi-cadre 34-09. Bulletin officiel (2 juillet 2011). Maroc.

37. Macinko et al. (2003). "The Contribution of Primary Care Systems to Health Outcomes within Organization for Economic Cooperation and 
Development (OECD) Countries, 1970-1998". James Macinko, Barbara Starfield and Leiyu Shi.

38. Margaret Elisabeth (2008). "Assessing health system performance in developing countries". University de Michigan.

39. Marie-Pascale Pomey et al. (2004). "Accreditation: a tool for organizational change in hospitals?" International Journal of Health Care Quality Assurance. Volume $17 \cdot$ Number 3.

40. Marie-Annick Montalan et al. (2013). «Un modèle d'évaluation de la performance multidimensionnelle d'une organisation hospitalière transversale ». Management \& Avenir 2013/3 (N 61).

41. McGlynn EA (1997). Six challenges in measuring the quality of health care. Health Aff (Millwood); 16 (3):7-21. Marshall M. Measuring general practice: a demonstration project to develop and test a set of primary care clinical quality indicators.

42. Merle, V., Moret, L., Pidhorz, L., Dujardin, F., Gouin, F., Josset, V., Graveleau, S., Petit, J., Riou, F., Lombrail, P. \& Czernichow, P. (2009). "Does comparison of performance lead to better care? A pilot observational study in patients admitted for hip fracture in three French public hospitals", International Journal of Health Care Quality, Vol. 21 No. 5, pp. 321-329.

43. Milakovich, M. (2004). "Rewarding quality and innovation: awards, charters, and international standards as catalysts for change", in Wimmer, M. Ed., In Knowledge Management in Electronic Government, Springer, Berlin, pp. 80-90.

44. Mohssine. N et al. (2012). «Implantation du programme d'accréditation hospitalière au Maroc ». Gestion hospitalières $n^{\circ} 518$ - juin / juillet.

45. OCDE (2011). «Améliorer la performance des soins de santé : Comment mesurer leur qualité ». Editions OCDE.

46. OMS (2000). « La santé dans le monde 2000. Pour un système de santé plus performant $»$.

47. OMS-AFRO (1995). «La réforme du secteur de la santé et la recherche sur les systèmes de santé : le processus de réforme peut-il être fondé sur des indices ? Document préliminaire destiné à la conférence « opérer des réformes du secteur sanitaire fondées sur des indices en Afrique subsaharienne ", organisée par l'OMS à Arusha, Tanzanie, du 20 au 23 novembre 1995.

48. Ovretveit, J. \& Gustafson, D. (2003). "Using research to inform quality programmes", BMJ, Vol. 326 No. 7392, pp. 759-761.

49. Papanicolas Irene and Peter C. Smith (2013). Health System Performance Comparison An agenda for policy, information and 
research European Observatory on Health Systems and Policies Series World Health Organization 2013.

50. Proctor S, \& Campbell J. (1999). "A developmental performance framework for primary care”. Int J Health Care Qual Assur Inc Leadership Health Serv.

51. Programme National d'Assurance Qualité (2000). Maroc; Septembre.

52. Santa Monica, CA: RAND Health (2003). Freeman T. Using performance indicators to improve health care quality in the public sector: a review of the literature. Health Serv Manage Res 2002;15(2):126-37.

53. Schneider, A. \& Stierle, F. (2007). "How to initiate and Steer Systemic Quality Improvement: An Advisor's Guide for the Health Sector and Other Social Sectors Eschborn". GTZ, avalable at:: www.giz.de.

54. Sicotte et al. (1999). «La performance organisationnelle des organismes publics de santé ». Rupture revue transdisciplinaire en santé Volume 6 n6.

55. Sicotte, C., F. Champagne, \& Coll (1998). "Conceptual framework for the analysis of health care organizations' performance." Heath Services Management Research 11: 24-48.

56. Siddiqi, S., Elasady, R., Khorshid, I., Fortune, T., Leotsakos, A., Letaief, M., Qsoos, S., Aman, R., Mandhari, A., Sahel, A., ElTehewy, M. \& Abdellatif, A. (2012). "Patient safety friendly hospital initiative: from evidence to action in seven developing country hospitals", International Journal of Quality and Health Care, Vol. 24 No. 2, pp. 144-151.

57. Smits Pernelle (2008). «Gestion et performance : une relation hologrammatique? ». Infolettre.

58. Starfield, B., \& L. Shi. (2002). "Policy Relevant Determinants of Health: An International Perspective.' Health Policy 60 (3): 201-16.

59. Starfield B et al. (2013). "Assessing primary care in Austria: room for improvement”. Florian L Stigler Family Practice (2013) 30 (2): 185-189.

60. Starfield (2009). "Primary care and equity in health: the importance to effectiveness and equity of responsiveness to peoples' needs". Barbara Starfield. HUMANITY \& SOCIETY, 2009, VOL. 33 (February/May: 56-73). Johns Hopkins University.

61. STARFIELD. B, LEIYU SHI, \& JAMES MACINKO (2005). "Contribution of Primary Care to Health Systems and Health". The Milbank Quarterly, Vol. 83, No. 3, (pp. 457-502).

62. Stratégie ministérielle du Maroc (2012 /2016). 
63. Veillard.J, F. Champagne, N. Klazinga, V. Kazandjian, O.

A. Arah, A.-L. Guisset (2005). A performance assessment framework for hospitals: the WHO regional office for Europe PATH project. International Journal for Quality in Health Care. Volume 17, Issue 6.

64. Véronique BAPTISTE (2003). « Le statut de l'auto-évaluation dans la démarche de changement L'accréditation hospitalière ». Thèse de Doctorat en Sciences de Gestion Présentée et soutenue publiquement le 31 mars.

65. Vieillard, J., S. Garcia-Armesto et al. (2010). « International Health System Comparisons: From Measurement Challenge to Management Tool », in L.M.E. Smith (dir. pub.), Performance Measurement for Health System Improvement: Experiences, Challenges and Prospects.

66. Villarmois O (2001). «Le concept de performance et sa mesure: un état de l'art »- Les Cahiers de la Recherche.

67. Virginie Gardette (2010). «Principes d'une démarche d'assurance qualité évaluation des pratiques professionnelles ». il faut chercher OMS ref.

68. William Hogg \& Elizabeth Dyke (2011). «Améliorer la mesure du rendement du système de soins primaires ». Vol 57: JULY. JUILLET.

69. World Health Organization (2006). "Quality of care: a process for making strategic choices in health systems". Available at: http://www.who.int/management/quality/assurance/QualityCare_B.D ef.pdf, accessed December 28. 